\title{
DISEÑO DE UN CUENTO INFANTIL PARA NIÑOS Y NIÑAS QUE FAVOREZCA EL PROCESAMIENTO DEL DUELO POR PÉRDIDA
}

\author{
LORENA NARVÁEZ \\ ISADORA SALAS \\ CARLA ZAMBRANO ${ }^{* * *}$
}

Recibido: 29 de marzo de 2016 Aprobado: 6 de junio de 2016

\footnotetext{
*Pontificia Universidad Católica del Ecuador, Facultad de Psicología, Quito, Ecuador (tlnarvaez@puce.edu.ec).

"*Pontificia Universidad Católica del Ecuador, Facultad de Psicología, Quito, Ecuador (isadoraquien@gmail.com).

***Pontificia Universidad Católica del Ecuador, Facultad de Psicología, Quito, Ecuador (carlabzl@hotmail.com).
} 

Revista PUCE. ISSN 1390-7719. Núm.103. 3 de mayo de 2016-

3 de noviembre de 2016. Lorena narváez, isadora Salas,

CARLA ZAMBRANO. PP. 83-104

\section{DISEÑO DE UN CUENTO INFANTIL PARA NIÑOS Y NIÑAS QUE FAVOREZCA \\ EL PROCESAMIENTO DEL DUELO POR PÉRDIDA}

Lorena Narváez, Isadora Salas, Carla Zambrano

Palabras clave: Duelo, cuento, angustia

Key words: Mourning, story, anguish

\section{RESUMEN}

El presente trabajo busca difundir información sobre un proyecto de disertación realizado en la carrera de Psicología Clínica, cuyo objetivo fue el diseño de un cuento para niños/as de 6 a 12 años de edad, que contenga características que favorezcan el procesamiento del duelo por pérdida. El cuento fue dividido en dos partes: la primera enfocada en el rango de edad de 6 a 9 años y la segunda dirigida a niños entre 10 y 12 años. Para este acometido, se hizo un recorrido teórico de los conceptos: duelo y pérdida; como de cuento y otros asociados a estos temas. A partir del marco teórico, se diseñó la metodología para la investigación de campo en el centro "La Casa del Sol", donde se obtuvo un diagnóstico de las necesidades de los niños/as.

Finalmente, tras entrelazar la teoría con los resultados obtenidos por medio del diagnóstico investigativo, se ejecutó el producto final: dos historias ilustradas (cuentos), enfocadas en las distintas necesidades según el rango de edad. El producto de la disertación ha sido validado por profesionales tanto del campo de la psicología clínica como de la literatura infantil 


\section{ABSTRACT}

This article/work intends to spread out information about a dissertation project done at the Clinical Psychology program and which goal was to design a story tale for 6-12 year old boys and girls so that they can resolve the mourning loss. The tale was divided in two parts, the first one was focused on the age range of 6-9 and the second one on the age range of 10-12. In order to do this, the theory related to the concepts of mourning and loss as well as story tale have been presented.

The methodology for this research work at "La Casa del Sol" Center where the children needs were first identified was designed from the theory.

Finally, as an end product, two illustrated stories focused on the needs of each age range came up by linking the results to the theory and the research diagnosis. The dissertation result has been approved by professionals in the field Clinical Psychology and children's Literature.

\section{INTRODUCCIÓN}

El dolor irrumpe el rato menos pensado en la vida del ser humano. Nadie está preparado para perder un ser querido, cambiar de un día para otro de una situación positiva a una etapa desagradable. Gozar de buena salud y de repente saber que esta se quebranta gravemente. Haberse sostenido de una idea o una imagen que en determinado momento ya no tiene lugar.

Indiscutiblemente, venimos a este mundo de entradas y salidas, para reír o llorar, para sentirnos llenos y en otros instantes vacíos, perdidos, confiados o decepcionados. El maestro tiempo nos permite caer en cuenta que en nuestro cuerpo se inscriben cicatrices alojadas en lo más profundo del ser, que nos recuerdan las caídas que hemos tenido pero que a pesar de todo, los pedazos rotos se reagrupan para modelarnos de otra manera.

Comúnmente se escucha decir que el tiempo lo cura todo. ¿Acaso el tiempo per se cura los avatares del alma? Quizás sí, pero no todo. Probablemente el espacio de apalabrar el dolor constituye una vía para elaborar los duelos.

En repetidas ocasiones surge esta interrogación: ¿por qué los adultos evitan contar a los niños que su abuelo, tío, o familiar ha muerto? ¿Por qué se intentan negar los hechos? Cuando las huellas del quebranto dejan entrever una atmósfera de pesar. 
ReVista PUCE. ISSN 1390-7719. Núm.103. 3 de mayo de 2016-

3 De noviembre de 2016. Lorena Narváez, Isadora Salas,

CARLA ZAMBRANO. PP. $83-104$

En el procesamiento del duelo en los niños, se distingue un período de desasosiego, que el menor lo expresa de una manera diferente a la de un adulto, pues si bien el adulto exterioriza su pena por vía de la palabra, la forma en que un niño lo hace, será a través del juego, los cuentos, los dibujos, en fin.

Hay una parte de la psiquis humana que no puede tramitar la pérdida del objeto, refiriéndose no solo a un objeto como tal, puesto que puede ser un ideal, un proyecto de vida, un camino, una ilusión, etc. En otras palabras, el sujeto trata de aferrarse a algún vestigio de esperanza, aunque realmente no la haya; hasta incluso puede intentar asirse de lo absurdo, de lo mágico para negar lo que está sintiendo, experimentando y de este modo huir de la congoja.

De cualquier modo, resulta complejo asumir la realidad, duele reconocer la finitud de la vida, cuesta admitir que no se tienen todas las soluciones ni todas las respuestas, pese a advertir que no todo gira a nuestro alrededor, y que la vida no se compone de ensayo-éxito, sino también de ensayo-error. O que en algunos casos, las circunstancias pueden venir totalmente adversas.

En definitiva, una vez instaurado el duelo, cuando se pierde el objeto amado, parecería no existir solución, la vida carece de sentido, la vida pierde su color. Los degradé de los tonos negros y grises realizan un baile donde el sujeto se pierde en la desesperación.

Poco a poco se va recobrando la capacidad de mirar hacia otros lados, incluso de mirarse por dentro. Inadvertidamente se abandona el discurso que trae al presente una y otra vez al objeto ausente. Paulatinamente, la historia se va transformando y tiene otras lecturas, la mente se aquieta y puede nuevamente observar la luz, el brillo, la claridad. Es ahí donde estamos en la capacidad de dibujar nuevos rostros del dolor.

Afortunadamente, el pesar tiene un límite, la vida está llena de comienzos y de finales, y después de cada final, le acontece un nuevo comienzo. Nada dura para siempre ni todo permanece estático.

Ahora bien, el marco teórico de esta investigación aportó las pautas necesarias para el diseño de las herramientas investigativas (entrevistas, encuestas, talleres y guías de observación). Aquí se presenta el cuento como herramienta que favorece la elaboración del duelo por pérdida. Desarrolla el concepto del duelo, su definición y realiza una asociación del mismo con la población infantil, así como también se plantea algunas características. Posteriormente, se hace un recorrido del cuento, desde una perspectiva psicoanalítica con breves acercamientos a la literatura.

El presente trabajo fue motivado por los niños/as, quienes ineludiblemen- 
te se enfrentan a pérdidas a lo largo del desarrollo, como los cambios físicos, psíquicos y/o sociales que implican crecer interna y externamente. El procesamiento de las pérdidas requiere de la elaboración del duelo. "El duelo es, por regla general, la reacción ante la pérdida de una persona amada o de una abstracción que haga sus veces, como la patria, la libertad, un ideal, etc." (Freud, 1917/1996, p.241).

Lo indicado cobra relevancia debido a que el proceder del sujeto al enfrentar las pérdidas desde la niñez, marcará el modo de asumirlas a lo largo de su vida. Dado que el desarrollo psíquico de los niños/as es muy particular porque no se cuenta con los recursos yoicos suficientes que promuevan apalabrar sus tristezas, es responsabilidad de los adultos, incluyendo al psicólogo, facilitar a los niños y niñas la tramitación de aquello que les produce mal-estar. Es aquí, donde se presenta una dificultad. Como dice Winnicott (1998), en su libro Acerca de los niños, los adultos tienden a suponer que los niños se recuperan rápidamente ante cualquier acontecimiento, incluyendo la pérdida. Como resultado, el adulto arrastra al niño a un estado de falsa animación suponiendo que eso que le aflige será olvidado pronto.

Es pertinente mencionar que la angustia guarda estrecha relación con la pérdida pues, "se presenta como una reacción frente a la ausencia del obje- to" (Freud, 1926/1996, p.129-130). Surge como una respuesta a una situación de peligro que es representada por la castración o algo derivado de frustraciones primarias anteriores a ella.

Sin duda, está ligada a la reproducción de un estado afectivo de displacer producido por represiones del yo, "(...) tan pronto como discierne el peligro de castración, el yo da la señal de angustia e inhibe el proceso de investidura amenazador para el ello" (Freud, 1926/1996, p.119). Esta inhibición llega a limitar de modo tal las funciones de yo, que puede ser característica de estados depresivos relacionados a la melancolía.

Dicha inhibición de las funciones yoicas, también es responsable de lo que Freud denominó compulsión a la repetición en 1920, refiriendo que el sujeto tiende a procurarse un castigo real como una forma de aplacar la angustia. He aquí, la necesidad de elaborar la pérdida y conjuntamente trabajar la angustia a la que se enfrenta el niño. De ser ausente dicho proceso, uno de los caminos es el autocastigo, dado por la culpa de perder al objeto, puede tener implicaciones a futuro en el orden de la repetición o llevarlo a la melancolía.

Una vez abordada la temática del duelo y algunos de sus elementos, se presenta al cuento como una alternativa para trabajar las pérdidas con niños/as. Entonces, el cuento es una narración que 
ReVista PUCE. ISSN 1390-7719. Núm.103. 3 de mayo de 2016-

3 De noviembre de 2016. Lorena Narváez, Isadora Salas,

CARLA ZAMBRANO. PP. $83-104$

se caracteriza por ser corta y su contenido es ficticio. Estimula diversas áreas del desarrollo tanto intelectual como emocional pues, ayuda por medio de la metáfora, y la simbolización a la elaboración. Adicionalmente, permite enfrentar y poner en palabras situaciones difíciles o dolorosas que conllevan angustia, por esta razón, también se convierte en una herramienta de uso terapéutico.

La idea de conjugar la literatura con la psicología, no es nueva, el autor y psicoanalista Bruno Bettelheim, quien es, sin duda, el más mencionado por su reconocido trabajo: Psicoanálisis de los cuentos de hadas, ha hecho significativos aportes en este campo. Bettelheim (1994), dice que el cuento libera las pulsiones del ello, de forma tal, que estas no se contraponen a las exigencias superyoicas, sino que las satisfacen y estimulan al yo porque se dan en el orden de la fantasía pues, es también, lúdico y como dice Dolto (1988), todo juego es mediador del deseo.

Aplicando el modelo psicoanalítico de la personalidad humana, los cuentos aportan importantes mensajes al consciente, preconsciente e inconsciente, sea cual sea el nivel de funcionamiento de cada uno en aquel instante. Al hacer referencia a los problemas humanos universales, especial- mente aquellos que preocupan a la mente del niño, estas historias hablan a su pequeño yo en formación y estimulan su desarrollo, mientras que, al mismo tiempo, liberan al preconsciente y al inconsciente de sus pulsiones. A medida que las historias se van descifrando dan crédito consciente y cuerpo a las pulsiones del ello y muestran los distintos modos de satisfacerlas, de acuerdo con las exigencias de yo y del super-yo. (Bettelheim, 1994, p.12)

Se identifica con el personaje, de tal forma que las victorias de él son tomadas como las suyas propias; además "(...) la identificación aspira a configurar el yo propio a semejanza del otro, tomado como «modelo»." (Freud S, 1917 /1993, p.100). Aquellos cuentos que tienen éxito narran historias con las que el niño, de forma consciente o inconsciente, se identifica, debido a que en la infancia el yo aún no se ha fortalecido y el sujeto se enfrenta a los "caprichos" del ello, en contraposición a las exigencias y demandas del superyó.

El pensamiento popular sobre el cuento, hace referencia a una historia que narra una situación entretenida con un mensaje al niño. Contrarrestando este pensamiento común, Bettelheim (1994), propone un importante aporte al respec- 
to: aprender a leer no tiene tanto valor, si aquello para lo que se nos ha enseñado no aporta nada importante a la vida propia, en referencia a la vida psíquica y emocional.

El niño/a da forma al malestar interno con ayuda de la fantasía, que sin saberlo, el sujeto logra simbolizar. De este modo, ordena y elabora eso que ha sido reprimido por el inconsciente y canaliza los impulsos por medio de la imaginación fantasiosa. "El cuento lo conforta mucho más que los esfuerzos por consolarlo basados en el razonamiento y opiniones adultos." (Bettelheim, 1994, p.53)

Se podría ahondar aún más en el funcionamiento de los cuentos a nivel psíquico, pero por ahora, se intentará detener en las características que debería tener un cuento, para responder a los objetivos del producto final. Es preciso, por ejemplo, que estimule la función simbólica, entendiendo la misma como el paso por la palabra de los pensamientos que se han registrado a nivel imaginario; siendo atractivo al lector. Es aquí donde se ubica la identificación, indispensable pues es "la más temprana exteriorización de la ligazón afectiva con otra persona" (Freud S, 1917/1993, p.99). Lo cual implica reconocerse en otro distinto, porque algo hay en este que despierta en el niño su vida afectiva. En la identificación con el personaje, el niño proyecta su propia historia, en este sentido, las victorias del personaje son tomadas como las suyas propias.
Por consiguiente, según Bettlheim los cuentos que tienen éxito, narran historias que involucran al niño y dan cuenta de la parte emocional-psicológica, poniendo en juego la lucha interna por manejar los impulsos. Finalmente, el niño/a da forma al malestar interno con ayuda de la fantasía, en la que, la imaginación se convierte en un mecanismo que da cuenta del deseo de restauración. "Al darle a un niño algo con lo cual pueda ordenarse desde dentro, se le da toda clase de satisfacciones" (Winnicott, 1998, p.60). El cuento es un juego que abre la posibilidad al sujeto de explorar y enfrentar la realidad de manera suficientemente lejana para que no cree un impacto traumático o doloroso, y pueda dar sentido a las percepciones parciales del mundo externo, ya sean estas agradables o desagradables; es así que a través de esta teatralidad que involucra el cuento, ocurre una puesta en escena de aspectos que movilizan al sujeto, lo que resulta en la reelaboración de acontecimientos penosos que no pueden ser tramitados por vía de la palabra.

En definitiva, usar un cuento de modo terapéutico deviene de suma importancia, puesto que, en el protagonista del cuento, el niño proyecta su propia historia. Por otro lado, el uso de cuentos como herramienta terapéutica no es un instrumento único y exclusivo del psicoanálisis; psicólogos exis- 
tenciales como Alejandro de Barbieri (2008), o dentro de la línea cognitiva conductual, Nemifort M. y J. Annunziata (2006), recurren a los cuentos como medio terapéutico. Profesionales ecuatorianos como Lorena Narváez (2012), utiliza sus propios cuentos en terapia de forma exitosa. Sin embargo, a nivel de disertaciones universitarias en la ciudad de Quito, no se registraron investigaciones similares o productos creados que respondan a la temática de la pérdida.

Tomando en cuenta lo investigado y teorizado, la disertación tuvo como objetivo diseñar un cuento para niños y niñas de 6 a 12 años que contenga características que favorezcan el procesamiento del duelo por pérdida, el cual se encuentra dividido en dos partes, la primera, orientada para el rango de edad de 6 a 9 años y la segunda para 10 a 12 años.

\section{MÉTODO}

La investigación dio inicio, considerando la novedad del cuento como herramienta psicológica, se tomó como principal autor a Bruno Bettelheim por su investigación citada anteriormente y a autores clásicos como Freud, quien ha hecho aportes con respecto a la identificación, vista desde el psicoanálisis como "la más temprana exteriorización de la ligazón afectiva con otra persona" (Freud S, 1917/1996, p.99).

Posteriormente, se procedió a la construcción del recorrido teórico desde la perspectiva psicoanalítica, con el fin de analizar los conceptos de duelo, pérdida, y el cuento como herramienta psicológica para la elaboración de pérdidas.

Una vez finalizado el marco teórico de esta investigación, se marcaron las pautas que guiarían el trabajo de campo (realizada en el Centro de desarrollo "La Casa del Sol") por medio de la ejecución de entrevistas a las parvularias, encuestas a los padres de familia y observación directa con los niños.

Adicionalmente, en la preproducción de los cuentos, tanto para los contenidos de la historia, como el diseño y el desarrollo de los personajes, se consideraron los resultados de la entrevista realizada a Daniela Dobronsky (2015), quien apelaba a la importancia de las particularidades de la historia.

Según su experiencia en docencia infantil, psicología del desarrollo y literatura, para que la narración logre llegar a sus destinatarios es indispensable tomar en cuenta la edad a la que se dirige el cuento como el punto de partida. El acceso e interés por la fantasía por un lado, 
y por otro la extensión del texto, varía según los estadios del desarrollo. Los niños mayores de 9 años cuentan con un vocabulario más extenso, también buscan una realidad más cercana a la suya, Dobronsky (2015), sostiene que esto nace del anhelo de incorporase a la siguiente etapa del desarrollo que es la pubertad. En cambio, los niños más pequeños se ven llamados por personajes más fantásticos que alimentan su creatividad, por esta razón el personaje principal de las historias es un monstruo, pero en el segundo cuento se agregó una niña.

En las dos historias, los personajes permiten la identificación del niño con los mismos de una forma muy sutil, sin llegar a ser invasivo o presentar la realidad de forma violenta y cruda. En este sentido, se consideró la ayuda de la comunicadora social María Cristina Ayala, en la producción del producto-cuento, quien aportó el uso adecuado de metáforas, y otras figuras literarias y lexicográficas como la sintaxis y semántica, que hicieron que la historia fuese adecuada para la población. Ayala (2015), colaboró con sus conocimientos de literatura y escritura en sí, para dar forma a las historias, logrando que cada elemento presente fuera fundamental para el desarrollo y desenlace de cada cuento.

\section{PARTICIPANTES}

La investigación se realizó con la participación de los niños de la "Casa del Sol", sus representantes y las dos parvularias. La institución fue seleccionada porque mostró amplia apertura e interés en el proyecto, dado que responde a algunas necesidades institucionales como: brindar ayuda psicológica a los niños, promover espacios para que desarrollen su creatividad y fantasía, así como también ser un lugar seguro para ellos y su entorno. Es pertinente señalar que, estas familias se encuentran en condición de vulnerabilidad, pues, la mayoría son monoparentales, de escasos recursos eco- nómicos, baja escolaridad y agresividad. Ámbito que también atrajo el interés de las investigadoras por la atención y el material brindado a esta población.

Se consideró las dos participantes por la vasta experiencia (más de 20 años) de las "tías" que se encuentran vinculadas a la institución. Posteriormente, se hicieron las encuestas a 27 padres de familia que asistieron a la convocatoria y finalmente, la observación de los niños, que se la registró por medio de talleres interactivos, planificados de acuerdo al rango de edad de los pequeños. Proceso que duró ocho semanas. 
Revista PUCE, ISSN 1390-7719. Núm.103. 3 de MAYO de 2016 -

3 De noviembre de 2016. Lorena NARVÁEZ, Isadora Salas,

CARLA ZAMBRANO. PP. 83-104

\section{MEDICIÓN}

En un inicio, se realizaron entrevistas semi estructuradas a las dos parvularias que trabajan con los niños/as del comedor, con el fin de conocer qué situaciones de pérdida ocurren con más frecuencia y cómo se manejan las mismas.

Con respecto a las entrevistas de las parvularias, cabe indicar que hubo seis preguntas, las cuales pretendían dar luces a las investigadoras del contexto de los niños en torno a sus vivencias y pérdidas desde la experticia y la convivencia cotidiana de las "tías" con los mismos. Los ítems se plantearon para alcanzar los objetivos propuestos al inicio de esta investigación, en función de crear un material útil; para esto, se distinguieron las edades de los niños y se intentó delimitar los eventos que su contexto asume como pérdidas, así como también las manifestaciones de los pequeños del centro. Por medio de las preguntas, también se conoció las necesidades institucionales, como la falta de instrumentos o personal para abordar los conflictos emocionales de los niños.

En cambio, para la entrevista a los profesionales escritores de cuentos, las preguntas se plantearon para validar la información sobre la escritura para pequeños y los elementos estéticos necesarios, así como el vocabulario y la sintaxis, según las edades trabajadas; a fin de obtener un mejor impacto en los lectores.

Acerca de las encuestas para los representantes familiares, el instrumento utilizado fue el cuestionario semi estructurado, con el objetivo de recopilar información desde la visión paterna-materna y con la posibilidad de que los padres de familia puediesen dar cuenta de algunas expresiones percibidas en sus hijos. Los indicadores propuestos tales como el rango de edad, tipo de pérdidas, actitudes frente a las pérdidas, actitudes de los padres frente a las pérdidas que han sufrido los hijos, etc., se crearon tras una compilación de las respuestas de las entrevistas a las parvularias, la revisión de manifestaciones en casos de algunos autores investigados, y también los conocimientos tanto teóricos como prácticos de las investigadoras. Por lo tanto, estuvieron enfocados a identificar la estructura familiar de los niños que asisten, cuáles son las experiencias que los padres de familia consideran como pérdidas, el abordaje de los mismos ante estas situaciones, la importancia que le otorgan a la explicación y la manera de acompañar en dichos eventos.

Finalmente, respecto a la observación, se diseñaron guías de tipo semi estructurada, las cuales fueron usadas durante cada taller. La intención fue la 
recopilación de información de las actuaciones directas de los niños/as para poder identificar comportamientos y expresiones en torno a las diferentes situaciones de pérdida que se propusieron.
Las guías de observación, fueron llenadas por las investigadoras y revisadas en concordancia con la teoría propuesta. Dichas guías, corresponden a un aporte cualitativo de análisis en el caso de niños.

\section{PROCEDIMIENTO}

Las entrevistas de las "tías" se realizaron en la institución, así como también las entrevistas a los padres, con quienes primero se hizo una charla explicativa sobre el proyecto, las actividades a efectuarse y el producto final, para después administrar las encuestas. Tomando en cuenta la preocupación de las parvularias sobre la dificultad en lecto-escritura de algunos padres o madres, se hicieron gigantografías de las encuestas que facilitaron el proceso de respuestas porque se combinó con la lectura en voz alta de las preguntas e ítems. En función de posibilitar el trabajo, se firmaron previamente los respectivos consentimientos informados para cada participante que colaboró con la investigación.
Con respecto a los talleres, el primero fue ejecutado por medio de una obra de títeres y el segundo con una presentación con fotos impresas. El método de registro del comportamiento de la población, fue por medio de la observación y guías de registro.

Una vez obtenidos los resultados de las herramientas investigativas y tomando en cuenta las edades de los pequeños/as en cuanto a su desarrollo psíquico, se diseñó un cuento que contiene dos partes; la primera para niños y niñas de 6 a 9 años y la segunda para 10 a 12 años de edad. Adicionalmente, se entrevistó a profesionales en el ámbito de la literatura infantil para obtener mayor información desde la perspectiva de las letras.

\section{RESULTADOS}

De acuerdo a lo expresado por las parvularias, en las entrevistas realizadas, se encontró que los niños y niñas menores tienen mayor dificultad al expresarse ver- 
ReVista PUCE. ISSN 1390-7719. Núm.103. 3 de mayo de 2016-

3 De noviembre de 2016. Lorena Narváez, Isadora Salas,

CARLA ZAMBRANO. PP. $83-104$

balmente cuando algo les ocurre, mientras que los más grandes de 10 a 12 años pueden comunicarse de mejor manera, pero lo hacen solo si alguna de ellas les hace preguntas directas cuando perciben que se encuentran tristes, distraídos u observan un bajo rendimiento académico o falla en la escritura. Comentaron, que son muy pocos los casos en que los pre-púber se acercan voluntariamente a ellas para conversar o buscar apoyo emocional. Durante la entrevista, ambas reconocieron su falta de preparación al momento de efectuar contención emocional.

Sobre las pérdidas más comunes, consideran que principalmente son separaciones de los padres o muerte de algún familiar. Desde su experticia, dicen que cuando los niños y niñas, están atravesando por alguna pérdida, la representan por medio de: tristeza, aislamiento, pensatividad, agresividad, rebeldía, disminución del rendimiento escolar y pérdida de interés.

Estos términos fueron tomados textualmente de las entrevistas; así mismo, declararon que la institución no cuenta con un psicólogo/a o practicante de psicología de manera regular y ellas manejan las situaciones de pérdida como creen conveniente: aconsejando al niño/niña u ofertándole apoyo cuando lo requiera.

Para concluir, mostraron su percepción sobre la falta de tiempo de los padres y/o madres para hablar o explicar a sus hijos o hijas las situaciones familiares o las pérdidas, creen que se debe a que muchos de ellos, no lo consideran importante para el niño/a ni para la familia. Ambas, concuerdan que este fenómeno es desfavorable para los pequeños pero lamentablemente es un suceso común en el contexto.

Sobre las encuestas a los padres de familia se puede mencionar que fueron aplicadas a los 27 asistentes a la reunión explicativa del proyecto y la idea del proyecto fue acogida con entusiasmo. A continuación se presentan las preguntas con su respectivo análisis.

Pregunta 1: Marque el número de hijos suyos que asisten al Comedor de niños "La Casa del Sol"

El total de representantes familiares encuestados fueron 27 , de los cuales el $81 \%$ tiene un hijo y el 19\% tiene 2 hijos. Los datos muestran que la mayoría de padres tienen un solo hijo/a en el comedor.

Pregunta 2: Marque el rango de edad de su hijo o hija.

El 78\% de los niños/as está en el rango de edad de 6 a 9 años con 11 meses y el $22 \%$ en la de 10 a 12 años con 11 meses. Al relacionar este dato con la pregunta anterior se concluye que la mayoría de niños/as que asiste al Comedor son menores de 10 años.

Pregunta 3: Identifique las pérdidas que usted sabe que ha vivido su hijo 
La encuesta evidencia que las pérdidas más comunes en los niños/as de 6 a 9 años son: El cambio de profesora durante el año escolar, siendo este el más común pues se presenta en el 44\% de la población. Otras pérdidas que se han dado con menor frecuencia contienen el cambio de casa en el 24\%, el nacimiento de un hermano/a y la transición de la casa a la escuela en un 20\%, la pérdida o muerte de la mascota en un 16\%, y finalmente la separación o divorcio de los padres así como el cambio de escuela en el 12\% de la población.

En el grupo de 10 a 12 años, la categoría más común es la pérdida por muerte de algún ser querido, presente en un $43 \%$ de los niños/as. A esto le siguen la pérdida o muerte de la mascota, el cambio de casa y la separación o divorcio de los padres, atravesadas por el 29\% de la población. Finalmente, con el $14 \%$ de la población encontramos: la transición de la casa a la escuela, el cambio de escuela y la ausencia repentina de un ser querido por migración.

Se puede apreciar que la transición de la casa a la escuela disminuye en la población de 10 a 12 años, posiblemente porque estos ya la experimentaron anteriormente. De igual forma, el cambio de profesor/a durante el año escolar está presente en un porcentaje considerable en ambas poblaciones con distintos cambios de edad, lo que sugiere inestabilidad escolar. La muerte de un ser querido encabeza el grupo de 10 a 12 años, pero también se presenta en los niños menores. Se observa, que la separación de los padres de 6 a 9 años es del 12\%, mientras que sube a más de la mitad en un 29\% en los más grandes; lo que puede dar una idea del tiempo de duración de la relación de pareja.

Pregunta 4: Marque las actitudes o comportamientos que su hijo/a tuvo ante estas pérdidas.

En cuanto a las actitudes y comportamiento que han presentado frente a las pérdidas se encontró en los niños/as con rango de edad entre 6 y 9 años, mayor presencia de llanto repetitivo, frecuente en el $44 \%$ de la población, seguido por un 36\% de dolor en el cuerpo, 32\% de presencia de conductas agresivas, 28\% de nerviosismo, 24\% de aislamiento e incremento del sueño, 20\% de irritabilidad, $12 \%$ de enuresis, presencia de pesadillas y conductas agresivas, $8 \%$ de incremento de apetito, 4\% de conductas auto agresivas y otras, donde se señaló que el niño frecuentemente hablaba de su profesora tras el cambio de ésta.

Por otro lado, la manifestación más común en el grupo de 10 a 12 años es la presencia de dolor en el cuerpo que se presenta en el $71 \%$ de ellos, a esto le sigue la falta de apetito existente en el 57\%, el llanto excesivo, aislamiento, las conductas agresivas y la aparición 
ReVista PUCE. ISSN 1390-7719. Núm.103. 3 de mayo de 2016-

3 De nOViembre de 2016. LOREna NARVÁEZ, Isadora Salas,

CARLA ZAMBRANO. PP. $83-104$

de nuevos miedos en el $29 \%$ de la población; mientras que la irritabilidad, las pesadillas y el nerviosismo apareció en el $14 \%$ de niños/as. Lo que muestra que los niños/as en este rango de edad tienden a exteriorizar por medio del cuerpo lo que les ocurre con mayor frecuencia, pues se presenta en más de la mitad de la población.

Pregunta 5: ¿Qué medidas ha utilizado para acercarse a su hijo/a cuando él/ ella atravesó alguna pérdida?

En cuanto a las medidas que utilizan los padres para acercarse a sus hijos/ as, encontramos en relación a los niños/ as de 6 a 9 años que:

El $48 \%$ de los padres de familia recurrió a calmar con frases, el 36\% habló sobre la pérdida, el 28\% buscó ayuda con las tías (parvularias) de la "Casa del Sol"y el 20\% recurrió a ayuda psicológica.

En los padres del grupo de 10 a 12 años, los resultados arrojan que es más común hablar con sus hijos/as sobre la pérdida, situación presente en el $71 \%$ de la población, seguido por buscar ayuda de las tías (parvularias) de la "Casa del Sol" con 49\% de la población, y calmar con frases, así como buscar ayuda psicológica en el 29\% de los padres.

Se encuentra que es más común que los padres de los niños/as con rango de edad de 10 a 12 años utilicen el lenguaje para acercarse a sus hijos/as y acompañarlos después de una pérdida, esto sugiere que tienen dificultad para hablar con sus hijos menores.

Finalmente, se llevó a cabo la observación de los pequeños por medio de dos talleres. En ambos se aprecian necesidades afectivas y la falta de espacios en los que los niños/as puedan expresarse.

Para el taller dirigido a 6-9 años, se consideraron las pérdidas más comunes que resultaron de las investigaciones previas (entrevista a parvularias y la encuesta a padres). Las tramas de la obra fueron 3 situaciones representadas por 3 personajes diferentes y fueron: el nacimiento de un hermano/a acompañado con el miedo de que los padres lo quieran menos que al nuevo integrante de la familia; el cambio de curso escolar por mal comportamiento, el temor a hacer nuevos amigos, la ausencia repentina del padre junto con la dificultad de la madre para explicar lo que acontece.

Al instante que ocurrieron las pérdidas se escucharon gritos y demostraciones de ansiedad puesto que empezaron a moverse, sentarse diferente y hacer ruido. A medida que transcurría la historia de títeres, los personajes de la obra se enfrentaban a dichas pérdidas, en ese momento también hubo la presencia de gritos en la mayoría pero a otros niños/ as les produjo risas nerviosas y algunas expresiones de miedo.

La historia de ausencia del padre causó sorpresa, impulsó preguntas 
como: "¿Por qué se fue?". Esta pregunta abrió el espacio de compartir experiencias personales asociadas a la tristeza y el enojo por sucesos similares. En la parte final, al ayudar a los personajes a buscar soluciones; surgieron risas, gritos por querer ser escuchados y entusiasmo - emoción cuando los personajes agradecieron la colaboración de los niños/as para entender la situación y solucionar los problemas.

Al respecto del taller de 10-12 años, se puede indicar que se usaron fotos con distintas situaciones a la que los niños le pusieron nombre, reconocieron distintos sentimientos ante las mismas y propusieron soluciones ante las situaciones de pérdida.

Se registró en la mayoría, ansiedad (inquietud), tristeza, ausencias y en pocos niños/as timidez al hablar. Posteriormente, vieron las fotografías, algunos pidieron verlas de cerca y las cogieron para después pasarlas a otros, esto permitió que pudieran ver detalles con detenimiento para procesar los elementos de cada una.

En la fotografía 1 "Ir a la escuela", las reacciones fueron de ansiedad (inquietud) y algunos mencionaron sus sentimientos de nerviosismo y miedo cuando les ocurrió la experiencia. La solución más común expresada fue la de enfrentar el miedo y/o hablar con alguien de cómo se sentía. La fotografía 2
"Separación de padres" evocó en los participantes mayoritariamente ansiedad (inquietud), acompañado de enojo con gritos y tristeza. Las respuestas dadas denotaban tensión entre los padres y estuvieron acompañadas de verbalizaciones que sugerían la necesidad del niño de la foto por entender la situación.

En la fotografía 3"Abandono", hubo gritos junto con ansiedad (inquietud), mientras la mayoría del grupo proponía soluciones, dos niños mostraron tristeza. Ante la pregunta de identificación, contestaron que no han sentido abandono. Y sus soluciones fueron: conseguir nuevos amigos o una nueva familia. La fotografía 4 "Muerte de algún familiar", trajo en su mayoría rostros y expresiones verbales de tristeza, se escucharon algunos gritos y se vio ansiedad en algunos niños, pero también se pudo oír soluciones que implicaban dejarle/darle algo a la persona que se fue para poder sentirse mejor. Otra alternativa fue la de mantenerse ocupados para no pensar en ello.

En la fotografía 5 "Nacimiento de nuevo hermano/a", mayoritariamente se notó enojo y hubo gritos, pero al escuchar algunas soluciones del grupo y el testimonio de un compañero, hubo emoción y entusiasmo con la idea de tener un hermano/a y no estar solos. Por último, la fotografía 6 "Rechazo", evocó miedo y tristeza, acompañado de la anécdota de una niña sobre su experien- 
ReVista PUCE, ISSN 1390-7719. Núm.103. 3 de MAYO de 2016 -

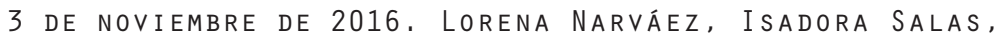

CARLA ZAMBRANO. PP. 83-104

cia de recibir burlas, pero que al buscar nuevos amigos se sintió mejor. La pala- bra "bulling" estuvo vigente y conocían bien su significado.

\section{DISCUSIÓN}

Una vez recopiladas la parte teórica y realizada la investigación de campo, se organizó la información obtenida para la ejecución del producto y se puede decir que el cuento promueve la creación y fortalecimiento de los vínculos afectivos, necesarios para el crecimiento personal de cada sujeto. Por lo tanto, responde a uno de los objetivos de la institución que busca "mejorar la atención afectiva de formación en el centro y en los hogares de los niños" (La Casa del Sol, 2012, p.6).

Además, el cuento promueve la fantasía, misma que ayuda a representar los procesos mentales inconscientes, sirve para tramitar la angustia y al mismo tiempo da cuenta del deseo de restauración. Es así, que el producto logró articularse con los objetivos propuestos por La Casa del Sol (2012), referente a brindar el espacio lúdico que posibilite la capacidad imaginativa y permita satisfacer la curiosidad de los niños.

Adicionalmente, se pudo constatar que el cuento es una herramienta útil que favorece el proceso de duelo por pérdida puesto que, los niños/as pueden identificarse con las historias y trabajar sus propios conflictos de manera indirec- ta y a su propio ritmo. Por consiguiente, el producto de la disertación realizada, es una vía de comunicación del mundo interno; sin llegar a ser invasivo; sin embargo, lo enfrenta a una situación que resuena algo de su historia por medio de la trama que los cuentos presentan.

El trabajo también hizo posible evidenciar, como lo dice Freud (1917/1996), que enfrentarse a lo intangible e irreparable que puede representar una pérdida del objeto investido, causa huida de la realidad, de aquello que se presenta como grotesco u ominoso, que es en realidad algo familiar y desconocido al mismo tiempo. Esta huida, en los adultos, se traduce en conductas defensivas e imaginarios asociados al pensar que el niño no teme o no sufre por su condición aparente de desentender la realidad adulta, por una supuesta mala memoria y el vasto tiempo por delante para olvidar el suceso. Así, evaden la situación además de aplacar su propia angustia. Entonces, el cuento se convierte en una herramienta pensada para los pequeños/as que han atravesado una pérdida, pero también para los adultos quienes no saben cómo lidiar con dicha 
situación al momento de dar contención o explicación a los niños/as. En base a todo lo trabajado, se puede entrever la relevancia de la producción de este material en el que se conjugan dos saberes: la psicología y la literatura.

Por añadidura, el cuento al mostrar un antes, durante y después de una historia, abre la posibilidad de la resolución de conflictos. Para su realización, se tomó en cuenta las reflexiones de Bolwby (2006), respecto al duelo y los procesos que lo acompañan que son: la protesta, la desesperación junto con la consternación, destacada por tener comportamientos autodestructivos y sentimientos ambivalentes frente al objeto; el apartamiento que implica el anhelo presente de recuperar al objeto perdido y finalmente, la reparación del suceso. Progreso que permite el crecimiento, por lo tanto aporta a la resiliencia de los lectores.

Con todo lo abordado anteriormente, durante el tiempo en el que tuvo lugar esta investigación, se reafirma que el cuento tiene muchas utilidades que pueden ser de gran ayuda para el trabajo terapéutico, así como también, refleja una contribución a la salud mental a través de la creación de historias que propician procesos intra-psíquicos en los niños.

\section{Anexo}

A continuación mostramos el producto final que se obtuvo tras la realización de la disertación, Cuento que favorezca el procesamiento de duelo por pérdidas. Dos historias, "Ciclo Monociclo" dirigida a niños de 6 a 9 años, y" ¿Existen los humanos?" pensada para niños de 10 a 12 años.

Título: Ciclo Monociclo

Me llamo Ciclo Monociclo

¡Ciclo-Monociclo en su rodar!

¡Ciclo-Monociclo a todo dar!

Ciclo Monociclo, ese soy yo, ¿o era? O ya no sé.

Me decían así porque mi monociclo era parte de mí.

Iba con él a todo lado y mientras más rápido, mejor.

A la escuela, a la casa, pedal tras pedal me movía a donde quería.

Hasta que un día desapareció.

Lo busqué en el garaje, en el comedor, en el parque y en el closet de los zapatos.

Pero mi monociclo no estaba.

Me senté tras la puerta a esperar a que volviera.

Se me fue el hambre, se me fueron las ganas, no quería ni jugar.

Hasta me perdí las albóndigas de mamá.

Es que siempre habíamos sido dos. 
Revista PUCE. ISSN 1390-7719. Núm.103. 3 de mayo de 2016 -

3 De noviembre de 2016. Lorena NARVÁEZ, Isadora Salas, CARLA ZAMBRANO. PP. $83-104$

Él era mi mejor amigo.

¿Cómo iba a seguir la vida solo?

No sabía cómo andar.

Así que decidí hacer una huelga de cama.

Me escondería bajo las cobijas y no saldría jamás.

¡TOC, TOC, TOC!, escuché en mi puerta después de unos días.

Me levanté sin dudarlo.

Podía ser mi mono-monociclo.

Pero en su lugar, encontré solo una gran caja de cartón.

La abrí decepcionado y descubrí un mundo de cosas en su interior: una catrina, una torre Eiffel, unos palillos chinos, una matrioshka, un diablo huma, y en el fondo, una carta.

\section{Amado compañero,}

Discúlpame por irme sin avisar.

Decidí emprender una aventura a través de los cinco continentes.

Me encanta estar contigo, pero mis pedales están hechos para viajar.

\section{Con amor,}

tu siempre tuyo monociclo.

Fue muy triste, lloré, pero entonces comprendí que aún sin mi monociclo, yo estaba completo.

Que para andar tenía dos pies.

Y de a poco voy aprendiendo, y de a poco voy caminando a la casa, a la escuela, paso tras paso, me muevo a donde quiero.

Aunque a veces recuerdo a Monociclo, estos nuevos pasos me han traído nuevos juegos, nuevos caminos, y nuevos amigos con los que río.

Soy Ciclo en mí andar.

Soy Ciclo a todo dar.

Soy Ciclo, solo Ciclo.

Y nadie me puede parar.

Esta historia se ha terminado, pero empieza una nueva.

Título: ¿Existen los humanos?

Mi mejor amiga se llama Nicoletta. Y es una niña.

Muchos monstruos creen que las niñas no existen, pero yo no les creo. Para mí las niñas son reales, como lo son sus vestidos, sus diademas y esas cancioncitas que se pasan tarareando hasta que se te pegan.

Mi mamá dice que, de pequeña, ella también jugaba con una niña y por eso, yo sí creo en mi amiga. Nicoletta dice que muchos humanos tampoco creen en los monstruos, pero eso no le importa, así que viene a jugar conmigo cuando se aburre de su mundo.

Le gusta treparse a los grandes árboles, jugar futbol, a la rayuela y me obliga a jugar al me-sú. Lo que no le gusta para nada es peinarse, por eso siempre usa una diadema morada.

Hace un par de semanas quedamos en encontrarnos y jugar toda 
la tarde al rinrín-correcorre. Nos gusta timbrar a la puerta de un desconocido y luego correr con todas las fuerzas de nuestras piernas. Ese día, la esperé parado, sentado, acostado y de cabeza, pero nunca llegó. ¿Será que me confundí de fecha?

Primero me enojé, pensé que se había olvidado, y después de tanta espera, regresé a casa.

- ¿Qué te pasa, Ciclo?- me preguntó mamá.

- Es que no viene Nicoletta — le respondí. - No se ha asomado en estas dos semanas.

- No sufras, hijito. Tal vez solo se fue de viaje o se mudó con sus papás me respondió y cambió de tema.

Fue la primera vez que no llegó. Nunca olvidaba cuando quedábamos en encontrarnos para jugar; además me hubiera dicho si se iba a cambiar de casa o a emprender un largo viaje. Al menos habría dejado una señal, pero nada. Las últimas veces la vi débil y ojerosa. En esto había algo raro, y yo lo iba a averiguar.

Comencé mi investigación en el lugar de los hechos. Fui a la calle en la que jugábamos rinrín. Esta vez timbré y esperé hasta que abrieran las puertas. Pregunté a todos los vecinos si la habían visto. Decían que seguro me la estaba imaginando porque los humanos no existen. Nadie la conocía.
Recorrí de arriba a abajo la ciudad de los monstruos, pero no estaba. Tendría que buscarla en su propio mundo.

Abrí la rendija que había bajo mi cama y me encontré rodando bajo la suya. El mundo de los humanos no era tan diferente al nuestro. Su cuarto seguía allí, con sus cuadernos y sus juguetes. Bajé las escaleras buscando a Nicoletta. Vi a su mamá, a su papá y a sus hermanos. Todos estaban tristes. Regresé a su cuarto y la busqué en el armario, que era su lugar favorito cuando jugábamos a las escondidas.

Lo único que encontré era esa diadema violeta que nunca se sacaba, porque así no tendría que peinarse. Entonces comprendí que ella ya no estaba ni en mi mundo ni en el suyo.

Por primera vez dudé de su existencia, me dolió la panza y lloré. ¿Tendrían razón todos los monstruos que decían que ella no era real? Ahora ya no podía asegurar nada. Me sentí solo y confundido, hasta culpable. Lo único que sabía es que ella ya no iba a regresar.

Ese fue el día más cariacontecido que he tenido. Entendí lo pesado que puede ser el vacío cuando se lo lleva en el corazón. Lo que más me aterraba era olvidarla, pero yo no dejaría que se fuera por completo. Construiría un cofre en mi memoria con todas las cosas que me recuerdan a ella y me hacen sonreír. 
Revista PUCE, ISSN 1390-7719. Núm.103. 3 de MAYO de 2016 -

3 De noviembre de 2016. Lorena NARVÁEZ, Isadora Salas,

CARLA ZAMBRANO. PP. $83-104$

Lo primero que puse fue la sonrisa aún chimuela en la que me fijé el día que la conocí.

Luego, el olor manzanilla que tenía su cabello, las caras largas que ponía cuando tenía deberes por hacer y las melodías de las canciones que tarareaba.

Siempre que veo el color violeta me acuerdo de ella, algunas veces siento nostalgia que ya no esté y otras siento mucha alegría por las cosas que vivimos. La recordaría en cada juego de rayuela y en cada historia de terror.

Descubrí que había un mundo en el que no podía desaparecer, porque con cada momento feliz que recordara, le daría vida en mi interior. Nicoletta era mi amiga y lo será por siempre.

Esta historia se ha terminado, pero empieza una nueva.

\section{Bibliografía:}

Bettelheim, B. (1994). Psicoanálisis de los cuentos de hadas. Barcelona, España: Drakontos.

Bowlby, John. (2006). Vínculos afectivos: formación, desarrollo y pérdida. Madrid, España: Morata.

Centro de Desarrollo Infantil "La Casa del Sol". (2012). Documento interno. Quito, Ecuador.

Constitución del Ecuador. (2012). http://www.educacion.gob.ec/wp-content/uploads/downloads/2012/08/ Constitucion.pdf. Ingreso: 27-01-2016

De Barbieri, A. (2008). "Cuentos que curan" Hacia un logoterapia narrativa psicoeducativa. http://logoforo.com/ cuentos-que-curan-hacia-una-logoterapia-narrativa-psico-educativa/. Ingreso: 28-01-2016.

Dobronsky, D. (2015). Comunicación personal. 09 de febrero de 2015.

Dolto, F. (1988). Las etapas de la infancia. Barcelona, España: Paidós.

Freud, S. (1996). Duelo y melancolía, texto original de 1917. Tomo XIV. Buenos Aires, Argentina: Amorrortu.

Freud, S. (1996). Inhibición, síntoma y angustia, texto original de 1926. Tomo XX. Buenos Aires, Argentina: Amorrortu.

Freud, S. (1996). Recordar, repetir, Reelaborar, texto original de 1914. Tomo XX. Buenos Aires, Argentina: Amorrortu. 
Kohan, S. (2003). Escribir para niños. Barcelona, España: Alba Editorial.

Winnicott, D. (1998). Acerca de los niños. Buenos Aires, Argentina: Paidós.

Winnicott, D. (1993). El niño y el mundo externo. Buenos Aires, Argentina: Paidós.

Narváez, L. (2012). En tierras muy lejanas. Quito: Centro de Ediciones PUCE. Nemifort M. y J. Annunziata. (2006). Mi primer libro de Terapia. Madrid: TEA Ediciones S.A. 